\title{
Association of the GALNT2 gene polymorphisms and several environmental factors with serum lipid levels in the Mulao and Han populations
}

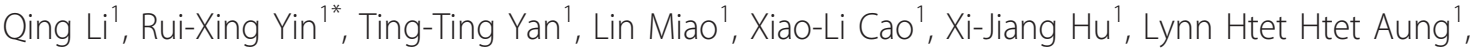
Dong-Feng $\mathrm{Wu}^{1}$, Jin-Zhen $\mathrm{Wu}^{1}$ and Wei-Xiong $\mathrm{Lin}^{2}$

\begin{abstract}
Background: The association of UDP-N-acetyl-alpha-D-galactosamine: polypeptide Nacetylgalactosaminyltransferase 2 gene (GALNT2) single nucleotide polymorphisms (SNPs) and serum lipid profiles in the general population is not well known. The present study was undertaken to detect the association of GALNT2 polymorphisms and several environmental factors with serum lipid levels in the Guangxi Mulao and Han populations.
\end{abstract}

Method: A total of 775 subjects of Mulao nationality and 699 participants of Han nationality were randomly selected from our stratified randomized cluster samples. Genotyping of the GALNT2 rs2144300 and rs4846914 SNPs was performed by polymerase chain reaction and restriction fragment length polymorphism combined with gel electrophoresis, and then confirmed by direct sequencing.

Results: There were no significant differences in the genotypic and allelic frequencies of both SNPs between the two ethnic groups, or between the males and females. The subjects with $\Pi$ genotype of rs2144300 in Mulao had lower serum triglyceride (TG) levels than the subjects with CC genotype in females $(P<0.01)$. The participants with $\mathrm{CT} / \mathrm{TT}$ genotype of rs2144300 in Han had lower TG and apolipoprotein (Apo) B levels, and higher high-density lipoprotein cholesterol (HDL-C), ApoA1 levels and the ratio of ApoA1 to ApoB in males; and higher low-density lipoprotein cholesterol (LDL-C) and ApoB levels in females than the participants with CC genotype $(P<0.05-0.001)$. The individuals with GA/AA genotype of rs4846914 in Mulao had higher total cholesterol (TC) and LDL-C levels than the individuals with GG genotype in males $(P<0.05$ for each). The subjects with AA genotype of rs4846914 in Han had higher LDL-C and ApoB levels, and lower HDL-C levels and the ratio of ApoA1 to ApoB than the subjects with GG genotype ( $P<0.05$ for each). The levels of TC in Mulao were correlated with the genotypes of rs4846914 in males $(P<0.05)$. The levels of ApoA1 in Han were correlated with the genotypes of both SNPs, and the levels of HDL-C and $A p o B$ and the ratio of $A p o A 1$ to $A p o B$ were associated with the genotypes of rs 2144300 in males $(P<0.05-0.001)$. The levels of LDL-C in Han were correlated with the genotypes of rs4846914 in females $(P<0.05)$. Serum lipid parameters were also correlated with several enviromental factors.

Conclusions: The associations of both GALNT2 rs2144300 and rs4846914 SNPs and serum lipid levels are different in the Mulao and Han populations. These discrepancies might partly result from different GALNT2 geneenviromental interactions.

\footnotetext{
* Correspondence: yinruixing@yahoo.com.cn

'Department of Cardiology, Institute of Cardiovascular Diseases, the First Affiliated Hospital, Guangxi Medical University, Nanning, Guangxi, People's Republic of China

Full list of author information is available at the end of the article
} 


\section{Introduction}

Prospective epidemiological studies have shown that unfavorable serum lipid levels such as raised levels of total cholesterol (TC) [1], triglyceride (TG) [2], low-density lipoprotein cholesterol (LDL-C) [3], and apolipoprotein (Apo) B [4], together with decreased levels of ApoA1 [4] and high-density lipoprotein cholesterol (HDL-C) [5] are the most important risk factors for coronary artery disease (CAD) and are the targets for therapeutic intervention [6]. It is well recognized that dyslipidemia is a complex trait caused by multiple environmental and genetic factors [6-8] and their interactions $[9,10]$. Family history and twin studies have shown that genetic polymorphism could account for $40-60 \%$ of the interindividual variation in plasma lipid phenotypes [11-13].

Recent genome-wide association (GWA) studies have identified new genetic determinants of several complex quantitative traits, including dyslipidemia [14-17]. These studies evaluated large samples of normolipidemic individuals and showed that several new single nucleotide polymorphisms (SNPs) had replicable modest associations with plasma concentrations of TC, TG, LDL-C, and HDL-C [14-17]. One of these newly identified SNPs is the UDP-N-acetyl-alpha-D-galactosamine: polypeptide $\mathrm{N}$-acetylgalactosaminyltransferase 2 gene (GALNT2) $[15,17]$. GALNT2 is a member of a family of GalNActransferases, which transfer an $\mathrm{N}$-acetyl galactosamine to the hydroxyl group of a serine/threonine residue in the first step of O-linked oligosaccharide biosynthesis [18]. It has been known that lecithin-cholesterol acyltransferase (LCAT), ApoC3, very low-density lipoprotein, and low-density lipoprotein receptors are all $\mathrm{O}$ glycosylated [19]. GALNT2 is a gene in the mapped locus on chromosome 1q42 within $150 \mathrm{~kb}$ of the lead SNP, which is located in an intron of the gene [6]. The GALNT2 polymorphisms have been found to be associated with alterations of plasma or serum HDL-C $[17,19-25]$ and TG $[15,17,24-28]$ concentrations in some GWA studies but not in others [29-31]. Thus, further studies will be required to characterize the full impact of these SNPs on lipid metabolism.

There are 56 ethnic groups in China. Han nationality is the largest ethnic group, and Mulao nationality is one of the 55 minorities with population of 207,352 according to the fifth national census statistics of China in 2000. Ninety percent of them live in the Luocheng Mulao Autonomous County, Guangxi Zhuang Autonomous Region, People's Republic of China. The records show that the history of this minority can be traced back to the Jin Dynasty (AD 265-420). It is believed that the Mulao people are the descendants of the ancient Baiyue tribe in south China and ethnically related to the neighboring ethnic groups. A previous study has shown that the genetic relationship between Mulao nationality and other minorities in Guangxi was much closer than that between Mulao and Han or Uighur nationlity [32]. To the best of our knowledge, however, the serum lipid profiles and the association of genetic polymorphisms and serum lipid levels have not been previously reported in this population. Therefore, the aim of the present study was to detect the association of GALNT2 rs2144300 and rs4846914 SNPs and several environmental factors with serum lipid profiles in the Mulao and Han populations.

\section{Materials and Methods \\ Study populations}

A total of 775 unrelated subjects of Mulao nationality who reside in Luocheng Mulao Autonomous County, Guangxi Zhuang Autonomous Region, People's Republic of China were randomly selected from our stratified randomized cluster samples. The ages of the subjects ranged from 15 to 80 years, with an average age of $52.20 \pm$ 11.68 years. There were 310 males $(40.0 \%)$ and 465 females $(60.0 \%)$. All subjects were rural agricultural workers. During the same period, a total of 699 people of Han nationality who reside in the same villages were also randomly selected from our previous stratified randomized cluster samples. The average age of the subjects was $51.42 \pm 15.34$ years (range 15 to 80 ). There were 266 men (38.1\%) and 433 women (61.9\%). All of them were also rural agricultural workers. The subjects had no evidence of diseases related to atherosclerosis, $\mathrm{CAD}$ and diabetes. None of them were using lipid-lowering medication such as statins or fibrates when the blood sample was taken. The study design was approved by the Ethics Committee of the First Affiliated Hospital, Guangxi Medical University. Informed consent was obtained from all subjects after they received a full explanation of the study.

\section{Epidemiological survey}

The survey was carried out using internationally standardized methods, following a common protocol [33]. All participants underwent a complete history, physical examination, and laboratory assessment of cardiovascular risk factors, including cigarette smoking, family history of myocardial infarction, blood pressure, presence of diabetes mellitus. Information on demographics, socioeconomic status, and lifestyle factors was collected with standardized questionnaires. The alcohol information included questions about the number of liangs (about $50 \mathrm{~g}$ ) of rice wine, corn wine, rum, beer, or liquor consumed during the preceding 12 months. Alcohol consumption was categorized into groups of grams of alcohol per day: $\leq 25$ and $>25$. Smoking status was categorized into groups of cigarettes per day: $\leq 20$ and > 
20. At the physical examination, several parameters including body height, weight, and waist circumference were measured. Sitting blood pressure was measured three times with the use of a mercury sphygmomanometer after the subjects had a 5-minute rest, and the average of the three measurements was used for the level of blood pressure. Systolic blood pressure was determined by the first Korotkoff sound, and diastolic blood pressure by the fifth Korotkoff sound. Body weight, to the nearest 50 grams, was measured using a portable balance scale. Subjects were weighed without shoes and in a minimum of clothing. Body height was measured, to the nearest $0.5 \mathrm{~cm}$, using a portable steel measuring device. From these two measurements body mass index (BMI, $\left.\mathrm{kg} / \mathrm{m}^{2}\right)$ was calculated.

\section{Biochemical analysis}

A venous blood sample of $5 \mathrm{~mL}$ was obtained from all subjects after at least 12 hours of fasting. A part of the sample $(2 \mathrm{~mL})$ was collected into glass tubes and used to determine serum lipid levels. Another part of the sample $(3 \mathrm{~mL})$ was transferred to tubes with anticoagulate solution ( $4.80 \mathrm{~g} / \mathrm{L}$ citric acid, $14.70 \mathrm{~g} / \mathrm{L}$ glucose, and $13.20 \mathrm{~g} / \mathrm{L}$ tri-sodium citrate) and used to extract deoxyribonucleic acid (DNA). Measurements of serum TC, TG, HDL-C, and LDL-C levels in the samples were performed by enzymatic methods with commercially available kits (RANDOX Laboratories Ltd., Ardmore, Diamond Road, Crumlin Co. Antrim, United Kingdom, BT29 4QY; Daiichi Pure Chemicals Co., Ltd., Tokyo, Japan). Serum ApoA1 and ApoB levels were detected by the immunoturbidimetric immunoassay using a commercial kit (RANDOX Laboratories Ltd.). All determinations were performed with an autoanalyzer (Type 7170A; Hitachi Ltd., Tokyo, Japan) in the Clinical Science Experiment Center of the First Affiliated Hospital, Guangxi Medical University [7,8].

\section{DNA preparation and genotyping}

Total genomic DNA was isolated from peripheral blood leukocytes using the phenol-chloroform method $[9,10]$. The extracted DNA was placed in long-term storage at $-80^{\circ} \mathrm{C}$. Genotyping of the two SNPs was performed by polymerase chain reaction and restriction fragment length polymorphism (PCR-RFLP). The sequences of the forward and backward primers used for the GALNT2 rs2144300 and rs4846914 were 5'-TTGAAGTAGGTGAAGGGGC-3' and 5'-CACATCAACAGCAAAGGGT-3', and 5'-CTGTGCCTTCTGGGACT GCTA-3' and 5'-AGGACTATGAGATGATGGTGG-3' (Sangon, Shanghai, People's Republic of China); respectively. Each reaction system of a total volume of $25 \mu \mathrm{L}$, comprised $100 \mathrm{ng}(2 \mu \mathrm{L})$ of genomic DNA; $1.0 \mu \mathrm{L}$ of each primer $(10 \mu \mathrm{mo} 1 / \mathrm{L}) ; 12.5 \mu \mathrm{L} 2 \times$ Taq PCR
MasterMix (constituent: $0.1 \mathrm{U}$ Taq polymerase/ $\mu \mathrm{L}, 500$ $\mu \mathrm{M}$ dNTP each and PCR buffer) and nuclease-free water $8.5 \mu \mathrm{L}$. For the amplification, initial denaturation at $95^{\circ} \mathrm{C}$ for $5 \mathrm{~min}$ was followed by 33 cycles of denaturation at $95^{\circ} \mathrm{C}$ for $45 \mathrm{~s}$, annealing at $59^{\circ} \mathrm{C}$ for $45 \mathrm{~s}$, and extension at $72^{\circ} \mathrm{C}$ for $1 \mathrm{~min}$, with final extension at $72^{\circ} \mathrm{C}$ for $10 \mathrm{~min}$. After electrophoresis on a $2.0 \%$ agarose gel with $0.5 \mu \mathrm{gmL}$ ethidium bromide, the amplifican products were visualized under ultraviolet light. Then each restriction enzyme reaction was performed with $6 \mu \mathrm{L}$ of amplified DNA; nuclease-free water $7.5 \mu \mathrm{L}$ and $1 \mu \mathrm{L}$ of $10 \times$ buffer solution; and restriction ezyme (5 U MN1I for rs2144300 and $5 \mathrm{U} H p y F 3 I$ for rs4846914) in a total volume of $15 \mu \mathrm{L}$ digested at $37^{\circ} \mathrm{C}$ overnight. After restriction enzyme digestion of the amplified DNA, the digestive products were separated by electrophoresis on sepharose gel. The length of each digested DNA fragment was determined by comparing migration of a sample with that of standard DNA marker. Stained with ethidium bromide, the gel was visualized under ultraviolet light and photographed. Genotypes were scored by an experienced reader blinded to epidemiological data and serum lipid levels.

\section{DNA sequencing}

Twelve samples (each genotype in two) detected by the PCR-RFLP were also confirmed by direct sequencing. The PCR products were purified by low melting point gel electrophoresis and phenol extraction, and then the DNA sequences were analyzed by using an ABI Prism 3100 (Applied Biosyatems) in Shanghai Sangon Biological Engineering Technology \& Services Co., Ltd., People's Republic of China.

\section{Diagnostic criteria}

The normal values of serum TC, TG, HDL-C, LDL-C, ApoA1, ApoB levels and the ratio of ApoA1 to ApoB in our Clinical Science Experiment Center were 3.10-5.17, 0.56-1.70, 1.16-1.42, 2.70-3.10 mmol/L, 1.20-1.60, 0.80$1.05 \mathrm{~g} / \mathrm{L}$, and 1.00-2.50; respectively. The individuals with TC > $5.17 \mathrm{mmol} / \mathrm{L}$ and/or TG $>1.70 \mathrm{mmol} / \mathrm{L}$ were defined as hyperlipidemic [7,8]. Hypertension was diagnosed according to the criteria of 1999 World Health Organization-International Society of Hypertension Guidelines for the management of hypertension [34,35]. The diagnostic criteria of overweight and obesity were according to the Cooperative Meta-analysis Group of China Obesity Task Force. Normal weight, overweight and obesity were defined as a BMI $<24,24-28$, and $>$ $28 \mathrm{~kg} / \mathrm{m}^{2}$; respectively [36].

\section{Statistical analysis}

Epidemiological data were recorded on a pre-designed form and managed with Excel software. The statistical 
analyses were done with the statistical software package SPSS 13.0 (SPSS Inc., Chicago, Illinois). Quantitative variables were expressed as mean \pm standard deviation (serum TG levels were presented as medians and interquartile ranges). Qualitative variables were expressed as percentages. Allele frequency was determined via direct counting, and the standard goodnessof-fit test was used to test the Hardy-Weinberg equilibrium. Difference in genotype distribution between the groups was obtained using the chi-square test. The difference in general characteristics between two ethnic groups was tested by the Student's unpaired $t$ test. The association of genotypes and serum lipid parameters was tested by analysis of covariance (ANCOVA). Age, sex, BMI, blood pressure, alcohol consumption, and cigarette smoking were adjusted for the statistical analysis. In order to assess the association of serum lipid levels with genotypes (rs2144300: $\mathrm{CT} / \mathrm{TT}=0, \mathrm{CC}=1 ; \mathrm{rs} 4846914: \mathrm{GA} / \mathrm{AA}=0, \mathrm{GG}=1$ ) and several environment factors, multivariable linear regression analyses with stepwise modeling were also performed in the combined population of Mulao and Han, Mulao, Han, males, and females; respectively. A
$P$ value of less than 0.05 was considered statistically significant.

\section{Results}

\section{General and biochemical characteristics}

The general and biochemical characteristics between Mulao and Han nationalities are detailed in Table 1. The levels of body height, LDL-C, ApoB, and the percentages of subjects who consumed alcohol were higher but the levels of BMI were lower in Mulao nationality than in Han ethnic group $(P<0.05-0.001)$. There were no significant differences in the levels of age, weight, waist circumference, systolic blood pressure, diastolic blood pressure, pulse pressure, blood glucose, TC, TG, HDL-C, ApoA1; the ratio of ApoA1 to ApoB; the percentages of subjects who smoked cigarettes; and the ratio of male to female between the two ethnic groups $(P>0.05$ for all).

\section{Electrophoresis and genotyping}

After the genomic DNA of the samples was amplified by PCR and imaged by agarose gel electrophoresis, the PCR products of $208 \mathrm{bp}$ (rs2144300) and $192 \mathrm{bp}$ (rs4846914) nucleotide sequences could be seen in the samples

Table 1 Comparison of demographics, lifestyle and serum lipid levels between the Mulao and Han populations

\begin{tabular}{|c|c|c|c|c|}
\hline Parameter & Mulao & Han & $t\left(\chi^{2}\right)$ & $P$ \\
\hline Number & 775 & 699 & & \\
\hline Male/female & $310 / 465$ & $266 / 433$ & 0.584 & 0.445 \\
\hline Age (years) & $52.20 \pm 11.68$ & $51.42 \pm 15.34$ & 1.187 & 0.277 \\
\hline Height (cm) & $155.08 \pm 7.36$ & $154.11 \pm 7.88$ & 5.863 & 0.016 \\
\hline Weight (kg) & $53.03 \pm 8.82$ & $53.14 \pm 8.80$ & 0.066 & 0.798 \\
\hline Body mass index $\left(\mathrm{kg} / \mathrm{m}^{2}\right)$ & $21.99 \pm 2.96$ & $22.37 \pm 3.40$ & 4.961 & 0.026 \\
\hline Waist circumference (cm) & $75.52 \pm 8.42$ & $75.21 \pm 7.94$ & 0.529 & 0.467 \\
\hline \multicolumn{5}{|l|}{ Cigarette smoking (n \%) } \\
\hline Nonsmoker & $600(77.4)$ & $525(75.1)$ & & \\
\hline$\leq 20$ Cigarettes/day & 144(18.6) & 154(22.0) & & \\
\hline$>20$ Cigarettes/day & $31(4.0)$ & 20(2.9) & 3.800 & 0.150 \\
\hline \multicolumn{5}{|l|}{ Alcohol consumption [n (\%)] } \\
\hline Nondrinker & $603(77.8)$ & $565(80.8)$ & & \\
\hline$\leq 25 \mathrm{~g} /$ day & $56(7.2)$ & $66(9.4)$ & & \\
\hline$>25 \mathrm{~g} /$ day & 116(15.0) & $68(9.7)$ & 10.688 & 0.005 \\
\hline Systolic blood pressure (mmHg) & $128.54 \pm 21.06$ & $129.74 \pm 19.03$ & 1.302 & 0.254 \\
\hline Diastolic blood pressure $(\mathrm{mmHg})$ & $81.44 \pm 11.98$ & $82.35 \pm 10.81$ & 2.338 & 0.126 \\
\hline Pulse pressure $(\mathrm{mmHg})$ & $47.10 \pm 15.19$ & $47.38 \pm 14.43$ & 0.136 & 0.713 \\
\hline Blood glucose (mmol/L) & $6.07 \pm 1.69$ & $6.03 \pm 1.61$ & 0.231 & 0.631 \\
\hline Total cholesterol (mmol/L) & $5.06 \pm 1.31$ & $4.99 \pm 1.11$ & 0.191 & 0.275 \\
\hline Triglyceride (mmol/L) & $1.10(0.80)$ & $1.05(0.91)$ & -0.502 & 0.616 \\
\hline $\mathrm{HDL}-\mathrm{C}(\mathrm{mmol} / \mathrm{L})$ & $1.75 \pm 0.42$ & $1.73 \pm 0.54$ & 0.412 & 0.521 \\
\hline LDL-C (mmol/L) & $2.98 \pm 0.95$ & $2.87 \pm 0.89$ & 4.786 & 0.029 \\
\hline Apolipoprotein(Apo)A1 (g/L) & $1.35 \pm 0.39$ & $1.34 \pm 0.26$ & 0.332 & 0.565 \\
\hline ApoB $(g / L)$ & $0.98 \pm 0.55$ & $0.85 \pm 0.21$ & 37.579 & 0.000 \\
\hline ApoA1/ApoB & $1.61 \pm 0.77$ & $1.66 \pm 0.49$ & 1.796 & 0.160 \\
\hline
\end{tabular}

HDL-C, high-density lipoprotein cholesterol; LDL-C, low-density lipoprotein cholesterol. The values of triglyceride were presented as median (interquartile range). The difference between the two ethnic groups was determined by the Wilcoxon-Mann-Whitney test. 
(Figure 1). The CC (208 bp), CT (208-, 181- and 27-bp) and TT (181- and 27-bp) genotypes of rs2144300 are shown in Figure 2A. The AA (126- and 66-bp), GA (126-, 107-, 66-, and 19-bp), and GG (107-, 66-, and 19bp) genotypes of rs4846914 are shown in Figure 2B. The 27- and 19-bp fragments were invisible in the gel owing to their fast migration speed.

\section{Results of sequencing}

The results were shown as CC, CT and TT genotypes of rs2144300 SNP and GG, GA and AA genotypes of rs4846914 SNP by PCR-RFLP, the genotypes were also confirmed by sequencing (Figure 3); respectively.

\section{Genotypic and allelic frequencies}

The genotypic frequencies of both SNPs were all in Hardy-Weinberg equilibrium. The $\mathrm{C}$ and $\mathrm{T}$ allele frequencies of GALNT2 rs2144300 were $79.10 \%$ and $20.90 \%$ in Mulao, and $80.54 \%$ and $19.46 \%$ in Han $(P>$ 0.05); respectively. The frequencies of CC, CT and TT genotypes were $63.35 \%, 31.48 \%$ and $5.16 \%$ in Mulao, and $63.95 \%, 33.19 \%$ and $2.86 \%$ in $\operatorname{Han}(P>0.05)$; respectively. The $\mathrm{G}$ and $\mathrm{A}$ allele frequencies of GALNT2 rs 4846914 were $78.38 \%$ and $21.62 \%$ in Mulao, and $75.50 \%$ and $24.50 \%$ in Han $(P>0.05)$; respectively. The frequencies of GG, GA and AA genotypes were $61.47 \%$, $33.82 \%$ and $4.71 \%$ in Mulao, and $56.24 \%, 38.52 \%$ and $5.24 \%$ in Han $(P>0.05$; Table 2$)$; respectively.

\section{Genotypes and serum lipid levels}

As shown in Table 3, the levels of TG in Mulao were different among the CC, CT and TT genotypes of rs2144300 $(P<0.05)$. The subjects with TT genotype had lower serum TG levels than the subjects with CC genotype, these results were found in females $(P<0.01)$ but not in males. The levels of TG, HDL-C, ApoA1, ApoB, and the ratio of ApoA1 to ApoB in Han were different between the CC and CT/TT genotypes of rs2144300 in males $(P<$ 0.05-0.001), the subjects with CT/TT genotype had lower serum TG and ApoB levels and higher serum HDL-C,

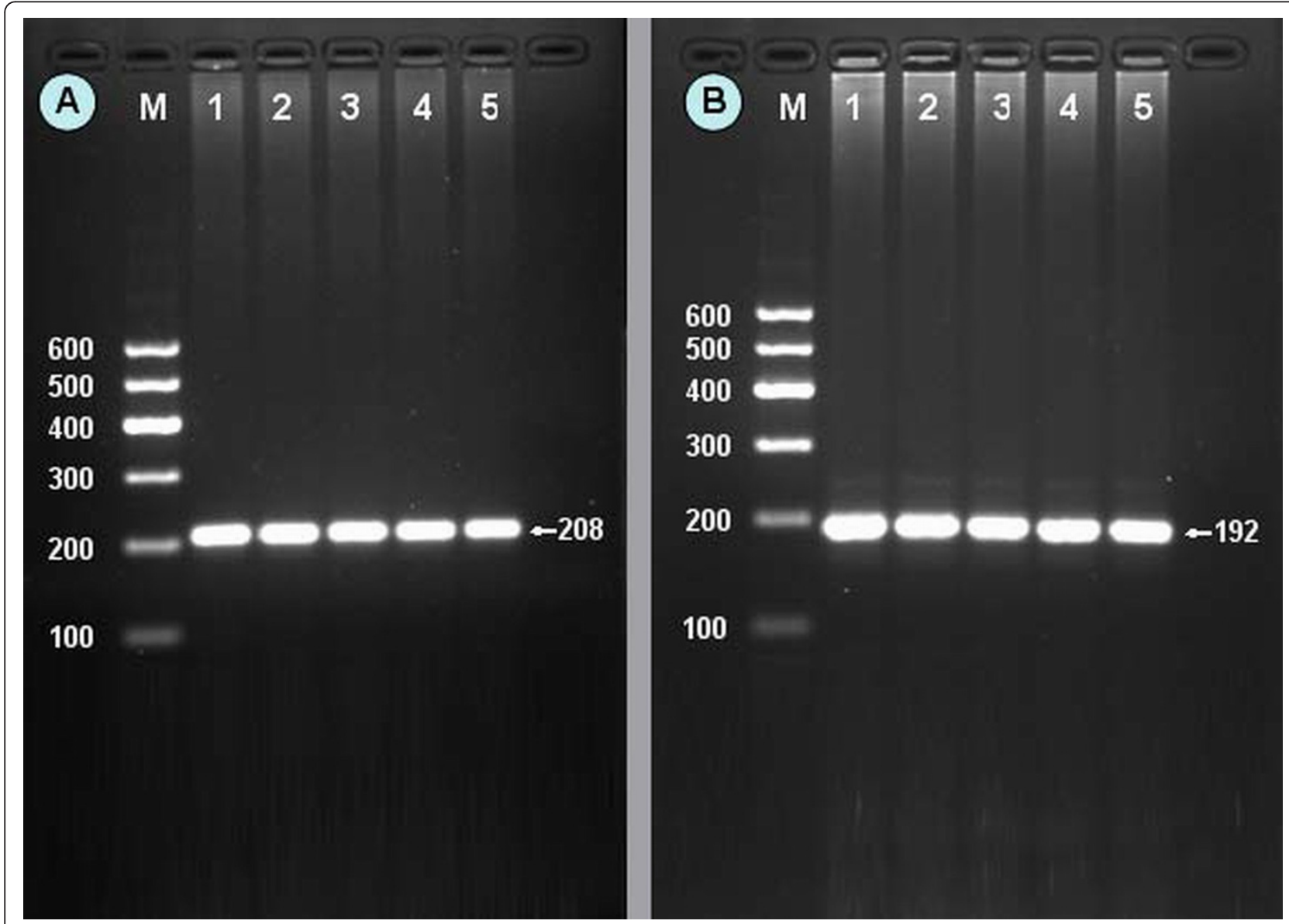

Figure 1 Electrophoresis of PCR products of the samples. (A) GALNT2 rs2144300. Lane M, 100 bp marker ladder; lanes 1-5, samples. The 208 bp bands are the PCR products. (B) GALNT2 rs4846914. Lane M, 100 bp marker ladder; lanes 1-5, samples. The 192 bp bands are the PCR products. 


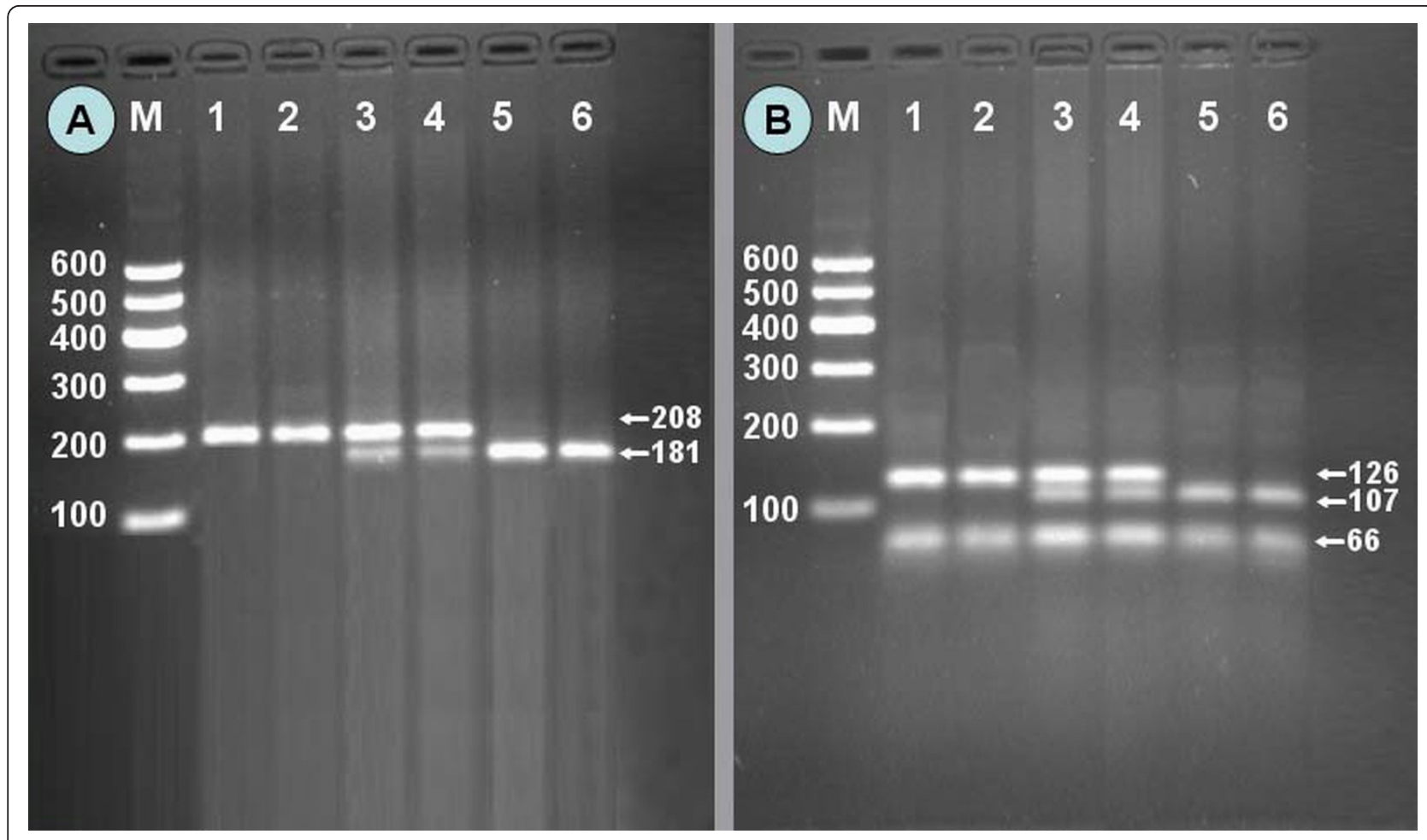

Figure 2 Genotyping of the GALNT2 rs2144300 and rs4846914 polymorphisms. (A) GALNT2 rs2144300. Lane M, 100 bp marker ladder; lanes 1 and 2, CC genotype (208 bp); lanes 3 and 4, CT genotype (208-, 181- and 27-bp); and lanes 5 and 6, TT genotype (181- and 27-bp). (B) GALNT2 rs4846914. Lane M, 100 bp marker ladder; lanes 1 and 2, AA genotype (126- and 66-bp); lanes 3 and 4, GA genotype (126-, 107-, 66- and 19-bp); and lanes 5 and 6, GG genotype (107-, 66- and 19-bp). The 27- and 19-bp fragments were invisible in the gel owing to their fast migration speed.

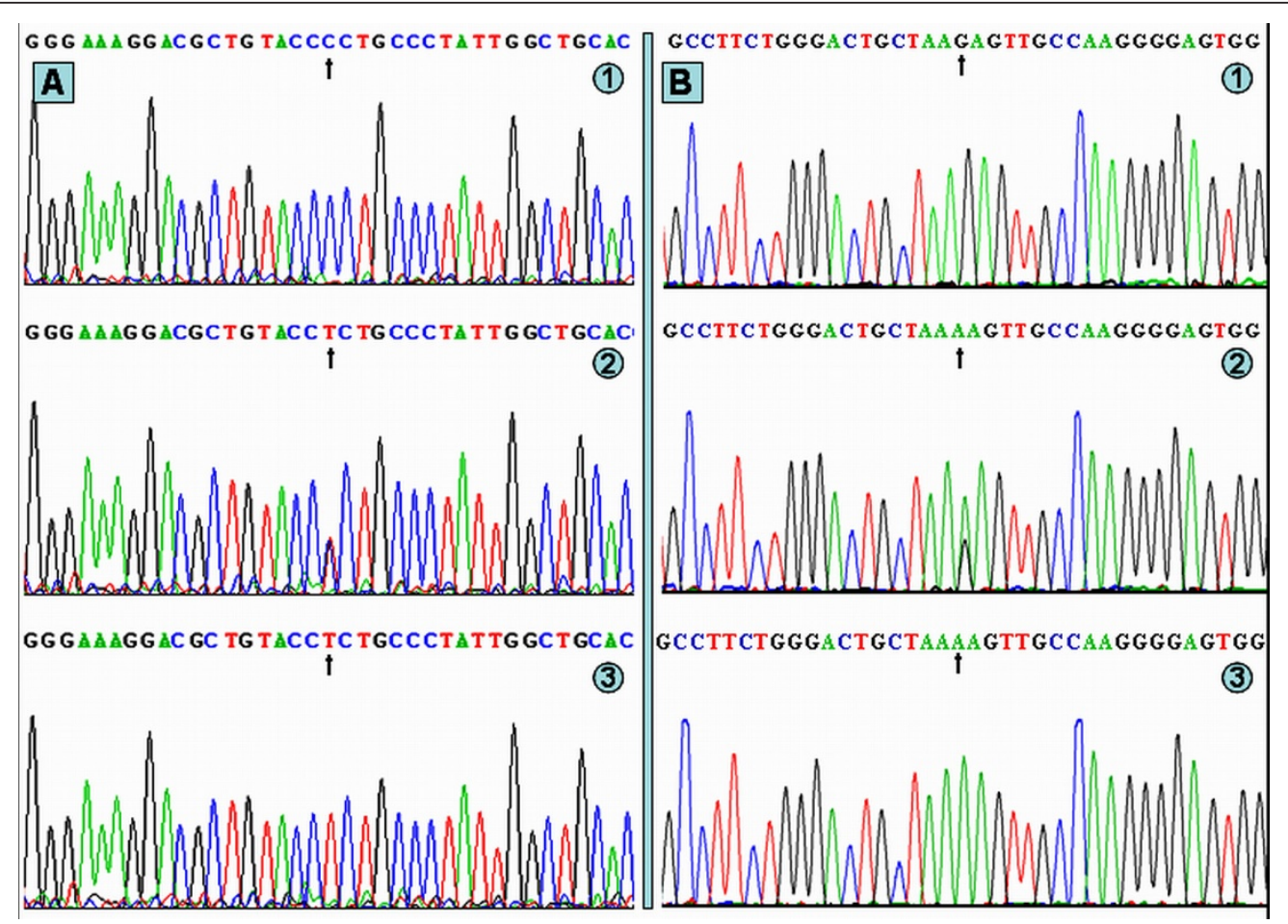

Figure 3 A part of the nucleotide sequences of GALNT2 rs2144300 and rs4846914 SNPs. (A) GALNT2 rs2144300 SNP: (1) CC genotype, (2) CT genotype, (3) TT genotype. (B) GALNT2 rs4846914 SNP: (1) GG genotype, (2) GA genotype, (3) AA genotype. 
Table 2 Comparison of the genotypic and allelic frequencies of GALNT2 rs2144300 and rs4846914 between the Mulao and Han populations

\begin{tabular}{|c|c|c|c|c|c|c|c|}
\hline \multirow{2}{*}{ SNP } & \multirow{2}{*}{ Group } & \multirow{2}{*}{$\mathrm{n}$} & \multicolumn{3}{|c|}{ Genotype [n (\%)] } & \multicolumn{2}{|c|}{ Allele [n (\%)] } \\
\hline & & & AA & $A B$ & BB & A & B \\
\hline \multirow[t]{12}{*}{ GALNT2 rs2144300 } & Mulao & 775 & $491(63.35)$ & 244(31.48) & $40(5.16)$ & $1226(79.10)$ & $324(20.90)$ \\
\hline & Han & 699 & $447(63.95)$ & 232(33.19) & $20(2.86)$ & $1126(80.54)$ & 272(19.46) \\
\hline & $\chi^{2}$ & - & \multicolumn{3}{|c|}{5.075} & \multicolumn{2}{|c|}{0.954} \\
\hline & $P$ & - & \multicolumn{3}{|c|}{0.079} & \multicolumn{2}{|c|}{0.329} \\
\hline & Mulao/male & 310 & 208(67.10) & $85(27.42)$ & $17(5.48)$ & $501(80.81)$ & 119(19.19) \\
\hline & Mulao/female & 465 & 283(60.86) & 159(34.19) & 23(4.95) & $725(77.96)$ & 205(22.04) \\
\hline & $\chi^{2}$ & - & \multicolumn{3}{|c|}{3.957} & \multicolumn{2}{|c|}{1.827} \\
\hline & $P$ & - & \multicolumn{3}{|c|}{0.138} & \multicolumn{2}{|c|}{0.177} \\
\hline & Han/male & 266 & $158(59.40)$ & $100(37.59)$ & $8(3.01)$ & 416(78.20) & $116(21.80)$ \\
\hline & Han/female & 433 & $289(66.75)$ & 132(30.48) & $12(2.77)$ & 710(81.99) & 156(18.01) \\
\hline & $\chi^{2}$ & - & \multicolumn{3}{|c|}{3.931} & \multicolumn{2}{|c|}{3.022} \\
\hline & $P$ & - & \multicolumn{3}{|c|}{0.140} & \multicolumn{2}{|c|}{0.082} \\
\hline \multirow[t]{12}{*}{ GALNT2 rs4846914 } & Mulao & 680 & $418(61.47)$ & $230(33.82)$ & $32(4.71)$ & 1066(78.38) & 294(21.62) \\
\hline & Han & 649 & $365(56.24)$ & $250(38.52)$ & $34(5.24)$ & $980(75.50)$ & $318(24.50)$ \\
\hline & $\chi^{2}$ & - & \multicolumn{3}{|c|}{3.760} & \multicolumn{2}{|c|}{3.112} \\
\hline & $P$ & - & \multicolumn{3}{|c|}{0.153} & \multicolumn{2}{|c|}{0.078} \\
\hline & Mulao/male & 249 & $151(60.64)$ & 88(35.34) & 10(4.02) & $390(78.31)$ & 108(21.69) \\
\hline & Mulao/female & 431 & 267(61.95) & $142(32.95)$ & $22(5.10)$ & $676(78.42)$ & $186(21.58)$ \\
\hline & $\chi^{2}$ & - & \multicolumn{3}{|c|}{0.709} & \multicolumn{2}{|c|}{0.002} \\
\hline & $P$ & - & \multicolumn{3}{|c|}{0.702} & \multicolumn{2}{|c|}{0.962} \\
\hline & Han/male & 260 & 159(61.15) & $87(33.46)$ & 14(5.39) & 405(77.88) & 115(22.12) \\
\hline & Han/female & 389 & 206(53.96) & $163(41.90)$ & 20(5.14) & $575(73.91)$ & 203(26.09) \\
\hline & $\chi^{2}$ & - & \multicolumn{3}{|c|}{4.762} & \multicolumn{2}{|c|}{2.665} \\
\hline & $P$ & - & \multicolumn{3}{|c|}{0.092} & \multicolumn{2}{|c|}{0.103} \\
\hline
\end{tabular}

Allele A, rs2144300 C and rs4846914 G; Allele B, rs2144300 T and rs4846914 A; Genotype AA, rs2144300 CC and rs4846914 GG; Genotype AB, rs2144300 CT and rs4846914 GA; Genotype BB, rs2144300 TT and rs4846914 AA

ApoA1 levels, and the ratio of ApoA1 to ApoB than the subjects with $C C$ genotype. The levels of LDL-C and ApoB in Han were different between the CC and CT/TT genotypes of rs2144300 in females $(P<0.01$ and $P<0.05$; respectively), the subjects with $\mathrm{CT} / \mathrm{TT}$ genotype had higher serum LDL-C and ApoB levels than the subjects with CC genotype.

The levels of TC and LDL-C in Mulao were different between the GG and GA/AA genotypes of rs4846914 in males $(P<0.05$ for each) but not in females, the subjects with GA/AA genotype had higher serum TC and LDL-C levels. The levels of HDL-C, LDL-C, ApoB, and the ratio of ApoA1 to ApoB in Han were different among the GG, GA, and AA genotypes of rs4846914 ( $P$ $<0.05$ for all), the subjects with AA genotype had higher serum LDL-C and ApoB levels and lower serum HDL-C levels and the ratio of ApoA1 to ApoB than the subjects with GG genotype.

\section{Risk factors for serum lipid parameters}

The correlation between the genotypes of GALNT2 rs2144300 and rs4846914 and serum lipid parameters in
Mulao and Han is shown in Table 4. The levels of TC in Mulao were correlated with the genotypes of rs4846914 in males $(P<0.05)$ but not in females. The levels of ApoA1 in Han were correlated with the genotypes of both rs2144300 and rs4846914 SNPs, and the levels of HDL-C, $\mathrm{ApoB}$, and the ratio of ApoA1 to ApoB were associated with the genotypes of rs2144300 in males $(P<0.05-0.001)$. The levels of LDL-C in Han were correlated with the genotypes of rs4846914 in females $(P<0.05)$.

Serum lipid parameters were also correlated with several environment factors such as age, gender, alcohol consumption, cigarette smoking, blood pressure, blood glucose, BMI, and waist circumference in both ethnic groups (Table 5).

\section{Discussion}

The results of the present study show that the levels of serum LDL-C and ApoB were higher in Mulao than in Han nationalities. There were no significant differences in the levels of serum TC, TG, HDL-C, ApoA1, and the ratio of ApoA1 to ApoB between the two ethnic groups. It is well known that dyslipidemia is a multifactorial 
Table 3 The GALNT2 rs2144300 and rs4846914 genotypes and serum lipid levels between the Mulao and Han populations

\begin{tabular}{|c|c|c|c|c|c|c|c|c|c|}
\hline SNP & Genotype & $\mathrm{n}$ & $\begin{array}{c}\text { TC } \\
(\mathrm{mmol} / \mathrm{L})\end{array}$ & $\begin{array}{c}\text { TG } \\
(\mathrm{mmol} / \mathrm{L})\end{array}$ & $\begin{array}{c}\mathrm{HDL}-\mathrm{C} \\
(\mathrm{mmol} / \mathrm{L})\end{array}$ & $\begin{array}{c}\mathrm{LDL}-\mathrm{C} \\
(\mathrm{mmol} / \mathrm{L})\end{array}$ & $\begin{array}{c}\text { ApoA1 } \\
(\mathrm{g} / \mathrm{L})\end{array}$ & $\begin{array}{c}\text { ApoB } \\
(\mathrm{g} / \mathrm{L})\end{array}$ & $\begin{array}{c}\text { ApoA1/ } \\
\text { ApoB }\end{array}$ \\
\hline \multicolumn{10}{|l|}{ GALNT2 rs2144300 } \\
\hline \multirow[t]{5}{*}{ Mulao } & CC & 491 & $5.06 \pm 1.39$ & $1.15(0.84)$ & $1.74 \pm 0.42$ & $2.97 \pm 0.96$ & $1.35 \pm 0.39$ & $0.99 \pm 0.55$ & $1.58 \pm 0.77$ \\
\hline & $\mathrm{CT}$ & 244 & $5.05 \pm 1.16$ & $1.05(0.83)$ & $1.77 \pm 0.43$ & $2.97 \pm 0.92$ & $1.35 \pm 0.40$ & $0.96 \pm 0.54$ & $1.67 \pm 0.81$ \\
\hline & $\pi$ & 40 & $5.20 \pm 1.01$ & $0.92(0.92)$ & $1.73 \pm 0.38$ & $3.11 \pm 0.96$ & $1.32 \pm 0.40$ & $0.97 \pm 0.47$ & $1.51 \pm 0.58$ \\
\hline & $F$ & - & 0.542 & 6.874 & 0.505 & 1.037 & 0.115 & 0.024 & 0.947 \\
\hline & P & - & 0.582 & 0.032 & 0.603 & 0.355 & 0.892 & 0.976 & 0.388 \\
\hline \multirow[t]{4}{*}{ Mulao/male } & CC & 208 & $5.12 \pm 1.42$ & $1.17(1.11)$ & $1.75 \pm 0.42$ & $2.86 \pm 0.92$ & $1.39 \pm 0.41$ & $1.05 \pm 0.64$ & $1.56 \pm 0.67$ \\
\hline & $\mathrm{CT} / \mathrm{TT}$ & 102 & $5.39 \pm 0.97$ & $1.12(1.20)$ & $1.73 \pm 0.42$ & $3.06 \pm 0.86$ & $1.37 \pm 0.35$ & $1.10 \pm 0.62$ & $1.46 \pm 0.60$ \\
\hline & F & - & 3.107 & -0.118 & 0.000 & 1.859 & 0.003 & 0.721 & 0.931 \\
\hline & $P$ & - & 0.079 & 0.906 & 0.986 & 0.174 & 0.959 & 0.397 & 0.335 \\
\hline \multirow[t]{4}{*}{ Mulao/female } & CC & 283 & $5.02 \pm 1.38$ & $1.14(0.65)$ & $1.72 \pm 0.42$ & $3.06 \pm 0.98$ & $1.32 \pm 0.37$ & $0.95 \pm 0.48$ & $1.61 \pm 0.84$ \\
\hline & $\mathrm{CT} / \mathrm{TT}$ & 182 & $4.89 \pm 1.20$ & $0.99(0.60)$ & $1.79 \pm 0.44$ & $2.95 \pm 0.96$ & $1.33 \pm 0.42$ & $0.88 \pm 0.47$ & $1.75 \pm 0.84$ \\
\hline & F & - & 0.354 & -2.851 & 0.540 & 0.127 & 0.091 & 0.876 & 1.224 \\
\hline & $P$ & - & 0.552 & 0.004 & 0.463 & 0.722 & 0.763 & 0.350 & 0.269 \\
\hline \multirow[t]{5}{*}{ Han } & $\mathrm{CC}$ & 447 & $4.97 \pm 1.02$ & $1.00(0.90)$ & $0.73 \pm 0.60$ & $2.83 \pm 0.86$ & $1.32 \pm 0.24$ & $0.84 \pm 0.20$ & $1.64 \pm 0.46$ \\
\hline & $C T$ & 232 & $5.05 \pm 1.27$ & $1.07(0.91)$ & $1.73 \pm 0.44$ & $2.90 \pm 0.96$ & $1.36 \pm 0.28$ & $0.85 \pm 0.22$ & $1.68 \pm 0.51$ \\
\hline & $\Pi$ & 20 & $4.89 \pm 1.51$ & $1.10(1.12)$ & $1.79 \pm 0.42$ & $3.28 \pm 0.67$ & $1.41 \pm 0.36$ & $0.93 \pm 0.15$ & $1.57 \pm 0.52$ \\
\hline & $F$ & - & 1.452 & 0.394 & 0.403 & 0.309 & 2.191 & 1.715 & 3.572 \\
\hline & P & - & 0.235 & 0.821 & 0.668 & 0.734 & 0.113 & 0.181 & 0.029 \\
\hline \multirow[t]{4}{*}{ Han/male } & CC & 158 & $5.25 \pm 0.96$ & $1.32(1.17)$ & $1.61 \pm 0.42$ & $3.01 \pm 0.81$ & $1.31 \pm 0.26$ & $0.93 \pm 0.20$ & $1.47 \pm 0.41$ \\
\hline & $\mathrm{CT} / \mathrm{TT}$ & 108 & $5.21 \pm 1.32$ & $1.09(0.93)$ & $1.71 \pm 0.42$ & $2.87 \pm 0.92$ & $1.40 \pm 0.30$ & $0.89 \pm 0.20$ & $1.64 \pm 0.47$ \\
\hline & $F$ & - & 0.120 & -2.085 & 4.795 & 1.156 & 6.432 & 4.478 & 13.073 \\
\hline & $P$ & - & 0.729 & 0.040 & 0.029 & 0.283 & 0.012 & 0.035 & 0.000 \\
\hline \multirow[t]{4}{*}{ Han/female } & $C C$ & 289 & $4.81 \pm 1.02$ & $0.91(0.78)$ & $1.79 \pm 0.66$ & $2.75 \pm 0.87$ & $1.32 \pm 0.24$ & $0.80 \pm 0.19$ & $1.73 \pm 0.46$ \\
\hline & $\mathrm{CT} / \mathrm{TT}$ & 144 & $4.89 \pm 1.25$ & $1.06(0.95)$ & $1.75 \pm 0.46$ & $2.96 \pm 0.97$ & $1.33 \pm 0.27$ & $0.84 \pm 0.23$ & $1.70 \pm 0.54$ \\
\hline & $F$ & - & 1.879 & -1.683 & 1.212 & 7.387 & 0.043 & 5.929 & 1.424 \\
\hline & P & - & 0.171 & 0.092 & 0.272 & 0.007 & 0.836 & 0.018 & 0.233 \\
\hline \multicolumn{10}{|l|}{ GALNT2 rs4846914 } \\
\hline \multirow[t]{5}{*}{ Mulao } & GG & 365 & $5.03 \pm 1.18$ & $1.12(0.83)$ & $1.75 \pm 0.43$ & $2.99 \pm 0.89$ & $1.36 \pm 0.38$ & $0.99 \pm 0.54$ & $1.58 \pm 0.61$ \\
\hline & GA & 250 & $5.02 \pm 1.11$ & $1.07(0.84)$ & $1.76 \pm 0.44$ & $2.96 \pm 0.86$ & $1.32 \pm 0.43$ & $0.95 \pm 0.52$ & $1.64 \pm 0.77$ \\
\hline & AA & 34 & $5.40 \pm 0.84$ & $1.05(0.79)$ & $1.72 \pm 0.37$ & $3.27 \pm 0.88$ & $1.32 \pm 0.38$ & $1.05 \pm 0.49$ & $1.42 \pm 0.59$ \\
\hline & $F$ & - & 1.810 & 1.253 & 0.089 & 1.911 & 0.787 & 0.343 & 1.430 \\
\hline & $P$ & - & 0.164 & 0.535 & 0.915 & 0.149 & 0.456 & 0.710 & 0.240 \\
\hline \multirow[t]{4}{*}{ Mulao/male } & GG & 159 & $4.97 \pm 1.02$ & $1.16(1.18)$ & $1.75 \pm 0.46$ & $2.86 \pm 0.79$ & $1.38 \pm 0.43$ & $1.00 \pm 0.59$ & $1.58 \pm 0.65$ \\
\hline & GA/AA & 101 & $5.23 \pm 0.97$ & $1.21(1.04)$ & $1.74 \pm 0.41$ & $3.08 \pm 0.78$ & $1.37 \pm 0.39$ & $1.05 \pm 0.57$ & $1.53 \pm 0.70$ \\
\hline & F & - & 5.626 & -0.553 & 0.012 & 4.170 & 0.007 & 0.305 & 0.108 \\
\hline & $P$ & - & 0.018 & 0.580 & 0.913 & 0.042 & 0.935 & 0.582 & 0.743 \\
\hline \multirow[t]{4}{*}{ Mulao/female } & GG & 206 & $5.08 \pm 1.29$ & $1.12(0.62)$ & $1.75 \pm 0.40$ & $3.09 \pm 0.95$ & $1.35 \pm 0.34$ & $0.98 \pm 0.50$ & $1.57 \pm 0.57$ \\
\hline & GA/AA & 183 & $4.93 \pm 1.14$ & $1.02(0.71)$ & $1.77 \pm 0.44$ & $2.96 \pm 0.91$ & $1.29 \pm 0.44$ & $0.91 \pm 0.48$ & $1.66 \pm 0.80$ \\
\hline & $F$ & - & 1.434 & -1.597 & 0.117 & 1.419 & 2.219 & 0.839 & 0.530 \\
\hline & $P$ & - & 0.232 & 0.110 & 0.773 & 0.234 & 0.137 & 0.360 & 0.467 \\
\hline \multirow[t]{5}{*}{ Han } & GG & 418 & $4.97 \pm 1.01$ & $1.00(0.80)$ & $1.70 \pm 0.40$ & $2.85 \pm 0.86$ & $1.31 \pm 0.24$ & $0.84 \pm 0.19$ & $1.63 \pm 0.45$ \\
\hline & GA & 230 & $5.01 \pm 1.15$ & $1.06(0.95)$ & $1.80 \pm 0.72$ & $2.84 \pm 0.86$ & $1.37 \pm 0.26$ & $0.84 \pm 0.20$ & $1.71 \pm 0.50$ \\
\hline & $\mathrm{AA}$ & 32 & $5.16 \pm 1.34$ & $1.40(1.22)$ & $1.62 \pm 0.40$ & $3.41 \pm 0.72$ & $1.32 \pm 0.31$ & $0.96 \pm 0.17$ & $1.43 \pm 0.47$ \\
\hline & $F$ & - & 0.261 & 2.716 & 3.415 & 4.060 & 2.658 & 3.255 & 3.901 \\
\hline & P & - & 0.770 & 0.257 & 0.033 & 0.018 & 0.071 & 0.039 & 0.021 \\
\hline \multirow[t]{4}{*}{ Han/male } & GG & 151 & $5.23 \pm 0.95$ & $1.16(1.05)$ & $1.63 \pm 0.38$ & $3.00 \pm 0.81$ & $1.32 \pm 0.23$ & $0.92 \pm 0.20$ & $1.50 \pm 0.41$ \\
\hline & GA/AA & 98 & $5.19 \pm 1.38$ & $1.15(1.23)$ & $1.67 \pm 0.45$ & $2.85 \pm 0.93$ & $1.40 \pm 0.33$ & $0.89 \pm 0.21$ & $1.63 \pm 0.51$ \\
\hline & $F$ & - & 0.136 & -0.149 & 0.253 & 0.532 & 2.429 & 0.762 & 3.096 \\
\hline & $P$ & - & 0.713 & 0.881 & 0.615 & 0.467 & 0.120 & 0.384 & 0.080 \\
\hline
\end{tabular}


Table 3 The GALNT2 rs2144300 and rs4846914 genotypes and serum lipid levels between the Mulao and Han populations (Continued)

\begin{tabular}{cccccccccc}
\hline Han/female & GG & 267 & $4.83 \pm 1.02$ & $0.96(0.73)$ & $1.74 \pm 0.41$ & $2.77 \pm 0.88$ & $1.31 \pm 0.24$ & $0.80 \pm 0.18$ & $1.71 \pm 0.45$ \\
& GA/AA & 164 & $4.94 \pm 1.03$ & $1.04(0.95)$ & $1.84 \pm 0.79$ & $2.94 \pm 0.82$ & $1.34 \pm 0.21$ & $0.84 \pm 0.19$ & $1.70 \pm 0.50$ \\
& $F$ & - & 0.247 & -1.122 & 2.904 & 1.735 & 1.389 & 0.684 & 0.575 \\
& $P$ & - & 0.619 & 0.262 & 0.089 & 0.188 & 0.239 & 0.409 & 0.449 \\
\hline
\end{tabular}

SNP, single nucleotide polymorphism; TC, total cholesterol; TG, triglyceride; HDL-C, high-density lipoprotein cholesterol; LDL-C, low-density lipoprotein cholesterol; ApoA1, apolipoprotein $A 1 ; A p o B$, apolipoprotein $B ; A p o A 1 / A p o B$, the ratio of apolipoprotein $A 1$ to apolipoprotein $B$;

The values of triglyceride were presented as median (interquartile range). The difference among the genotypes was determined by the Kruskal-Wallis test or the Wilcoxon-Mann-Whitney test.

origin, including environmental factors such as demographics, diet, alcohol consumption, cigarette smoking, obesity, exercise, hypertension $[7,8]$; genetic factors such as variants in genes coding for proteins; and their interactions $[9,10]$. For Mulao people, engagements were familyarranged in childhood, usually with the girl being four or five years older than the boy. There was a preference for marriage to mother's brother's daughter. Engagement and marriage were marked by bride-wealth payments. Marriage ceremonies were held when the girl reached puberty. She remained with her natal family until her first child was born. Till then she was free to join the young men and women who came together for responsive singing, flirtations, and courtships at festival times. Divorce and remarriage were permitted, with little restriction. The two-generation household is the most common unit of residence. Households are under the control of the father, and divide when the sons marry, with only the youngest son remaining with the parents. Daughters could not inherit property, and if there were no sons the property went to a nephew or lineage cousin's son. Therefore, we guessed that the hereditary characteristics and some lipid metabolism-related gene polymorphisms in this population may be different from those in Han nationality.

The genotypic and allelic frequencies of GALNT2 rs2144300 and rs4846914 SNPs in diverse racial/ethnic groups are not well known. In the present study, we showed that there were no significant differences in the genotypic and allelic frequencies of the two SNPs between the Mulao and Han populations, or between the males and females in both ethnic groups. These findings are similar to the results of a previous study in patients with stroke and control group [29]. Polgár et al. [29] showed that the allelic frequency of GALNT2 rs4846914 in patients with stroke did not significantly differ from that in control group. Also, the genotypic frequencies were similar to frequencies obtained in other populations $[15,17]$ and to data available in the International HapMap Project's data-base (http://www. hapmap.org) for the Caucasian CEPH population of European origin [29]. Since there were no observable differences in the genotypic and allelic frequencies of GALNT2 rs2144300 and rs4846914 SNPs between the

Table 4 Correlation between the GALNT2 rs2144300 and rs4846914 genotypes and serum lipid levels in the Mulao and Han populations

\begin{tabular}{|c|c|c|c|c|c|c|}
\hline Lipid & Genotype & Unstandardized coefficient & Std. error & Standardized coefficient & $t$ & $P$ \\
\hline \multicolumn{7}{|l|}{ Mulao and Han } \\
\hline LDL-C & rs4846914 genotype & -0.354 & 0.133 & -0.199 & -2.668 & 0.008 \\
\hline \multicolumn{7}{|l|}{ Han } \\
\hline HDL-C & rs4846914 genotype & 0.079 & 0.041 & 0.072 & 1.986 & 0.048 \\
\hline ApoA1 & rs4846914 genotype & 0.039 & 0.019 & 0.076 & 2.068 & 0.039 \\
\hline \multicolumn{7}{|l|}{ Mulao/male } \\
\hline $\mathrm{TC}$ & rs4846914 genotype & 0.292 & 0.127 & 0.141 & 2.302 & 0.022 \\
\hline \multicolumn{7}{|l|}{ Han/male } \\
\hline HDL-C & rs2144300 genotype & -0.397 & 0.141 & -0.527 & -2.816 & 0.005 \\
\hline \multirow[t]{2}{*}{ ApoA1 } & rs2144300 genotype & -0.085 & 0.027 & -0.172 & -3.132 & 0.002 \\
\hline & rs4846914 genotype & 0.055 & 0.028 & 0.113 & 1.978 & 0.049 \\
\hline ApoB & rs2144300 genotype & 0.043 & 0.021 & 0.108 & 2.057 & 0.041 \\
\hline ApoA1/ApoB & rs2144300 genotype & -0.165 & 0.043 & -0.204 & -3.816 & 0.000 \\
\hline \multicolumn{7}{|l|}{ Han/female } \\
\hline LDL-C & rs4846914 genotype & 0.162 & 0.065 & 0.111 & 2.493 & 0.013 \\
\hline
\end{tabular}

TC, total cholesterol; HDL-C, high-density lipoprotein cholesterol; LDL-C, low-density lipoprotein cholesterol; ApoA1, apolipoprotein A1; ApoB, apolipoprotein B; ApoA1/ApoB, the ratio of apolipoprotein $A 1$ to apolipoprotein $B$ 
Table 5 The environmental risk factors for serum lipid parameters in the Mulao and Han populations

\begin{tabular}{|c|c|c|c|c|c|c|}
\hline Lipid & Risk factor & Unstandardized coefficient & Std. error & Standardized coefficient & $t$ & $P$ \\
\hline \multicolumn{7}{|l|}{ Mulao and Han } \\
\hline \multirow[t]{6}{*}{$\mathrm{TC}$} & Age & 0.015 & 0.002 & 0.167 & 6.397 & 0.000 \\
\hline & Waist circumference & 0.012 & 0.005 & 0.080 & 2.178 & 0.030 \\
\hline & Alcohol consumption & 0.125 & 0.053 & 0.070 & 2.380 & 0.017 \\
\hline & Diastolic blood pressure & 0.008 & 0.003 & 0.073 & 2.704 & 0.007 \\
\hline & Cigarette smoking & 0.153 & 0.069 & 0.065 & 2.227 & 0.026 \\
\hline & Body mass index & 0.029 & 0.014 & 0.075 & 2.075 & 0.038 \\
\hline \multirow[t]{4}{*}{ TG } & Waist circumference & 0.066 & 0.007 & 0.251 & 9.853 & 0.000 \\
\hline & Alcohol consumption & 0.347 & 0.091 & 0.110 & 3.823 & 0.000 \\
\hline & Blood glucose & 0.103 & 0.033 & 0.079 & 3.146 & 0.002 \\
\hline & Cigarette smoking & 0.320 & 0.119 & 0.077 & 2.690 & 0.007 \\
\hline \multirow[t]{5}{*}{$\mathrm{HDL}-\mathrm{C}$} & Waist circumference & -0.01 & 0.002 & -0.167 & -4.49 & 0.000 \\
\hline & Alcohol consumption & 0.120 & 0.022 & 0.170 & 5.464 & 0.000 \\
\hline & Age & 0.003 & 0.001 & 0.097 & 3.786 & 0.000 \\
\hline & Gender & 0.108 & 0.031 & 0.109 & 3.440 & 0.001 \\
\hline & Body mass index & -0.012 & 0.006 & -0.079 & -2.165 & 0.031 \\
\hline \multirow[t]{4}{*}{ LDL-C } & Age & 0.012 & 0.002 & 0.182 & 6.923 & 0.000 \\
\hline & Body mass index & 0.046 & 0.008 & 0.160 & 6.068 & 0.000 \\
\hline & Alcohol consumption & -0.104 & 0.035 & -0.077 & -2.970 & 0.003 \\
\hline & Diastolic blood pressure & 0.005 & 0.002 & 0.058 & 2.118 & 0.034 \\
\hline \multirow[t]{3}{*}{ ApoA1 } & Alcohol consumption & 0.106 & 0.013 & 0.216 & 8.242 & 0.000 \\
\hline & Waist circumference & -0.004 & 0.001 & -0.107 & -4.079 & 0.000 \\
\hline & Age & 0.002 & 0.001 & 0.070 & 2.696 & 0.007 \\
\hline \multirow[t]{3}{*}{ ApoB } & Waist circumference & 0.010 & 0.001 & 0.188 & 7.062 & 0.000 \\
\hline & Blood glucose & 0.024 & 0.007 & 0.093 & 3.592 & 0.000 \\
\hline & Gender & -0.078 & 0.023 & -0.088 & -3.346 & 0.001 \\
\hline \multirow[t]{6}{*}{ ApoA1/ApoB } & Waist circumference & -0.013 & 0.003 & -0.163 & -4.402 & 0.000 \\
\hline & Blood glucose & -0.024 & 0.010 & -0.059 & -2.272 & 0.023 \\
\hline & Body mass index & -0.024 & 0.007 & -0.118 & -3.284 & 0.001 \\
\hline & Gender & 0.160 & 0.042 & 0.119 & 3.782 & 0.000 \\
\hline & Alcohol consumption & 0.108 & 0.029 & 0.114 & 3.674 & 0.000 \\
\hline & Age & -0.002 & 0.001 & -0.051 & -1.964 & 0.050 \\
\hline \multicolumn{7}{|l|}{ Han } \\
\hline \multirow[t]{5}{*}{ TC } & Diastolic blood pressure & 0.018 & 0.004 & 0.171 & 4.492 & 0.000 \\
\hline & Waist circumference & 0.024 & 0.005 & 0.168 & 4.611 & 0.000 \\
\hline & Age & 0.009 & 0.003 & 0.129 & 3.363 & 0.001 \\
\hline & Alcohol consumption & 0.235 & 0.063 & 0.134 & 3.725 & 0.000 \\
\hline & Blood glucose & 0.071 & 0.026 & 0.102 & 2.785 & 0.006 \\
\hline \multirow[t]{5}{*}{$\mathrm{TG}$} & Waist circumference & 0.073 & 0.010 & 0.259 & 7.165 & 0.000 \\
\hline & Cigarette smoking & 0.747 & 0.156 & 0.170 & 4.799 & 0.000 \\
\hline & Diastolic blood pressure & 0.029 & 0.008 & 0.139 & 3.660 & 0.000 \\
\hline & Blood glucose & 0.179 & 0.051 & 0.127 & 3.474 & 0.001 \\
\hline & Age & -0.015 & 0.006 & -0.104 & -2.717 & 0.007 \\
\hline $\mathrm{HDL}-\mathrm{C}$ & Waist circumference & -0.013 & 0.003 & -0.188 & -5.038 & 0.000 \\
\hline \multirow[t]{6}{*}{ LDL-C } & Age & 0.012 & 0.002 & 0.212 & 5.709 & 0.000 \\
\hline & Body mass index & 0.032 & 0.013 & 0.122 & 2.533 & 0.012 \\
\hline & Blood glucose & 0.043 & 0.021 & 0.078 & 2.071 & 0.039 \\
\hline & Waist circumference & 0.011 & 0.005 & 0.098 & 2.000 & 0.046 \\
\hline & Cigarette smoking & -0.243 & 0.081 & -0.139 & -3.010 & 0.003 \\
\hline & Gender & -0187 & 0.086 & -0103 & -2.174 & 0.030 \\
\hline ApoA1 & Alcohol consumption & 0.109 & 0.018 & 0.268 & 6.609 & 0.000 \\
\hline
\end{tabular}


Table 5 The environmental risk factors for serum lipid parameters in the Mulao and Han populations (Continued)

\begin{tabular}{|c|c|c|c|c|c|c|}
\hline & Body mass index & -0.010 & 0.003 & -0.135 & -3.625 & 0.000 \\
\hline & Gender & 0.093 & 0.026 & 0.174 & 3.506 & 0.000 \\
\hline & Cigarette smoking & 0.083 & 0.024 & 0.163 & 3.415 & 0.001 \\
\hline \multirow[t]{6}{*}{ ApoB } & Waist circumference & 0.006 & 0.001 & 0.228 & 5.110 & 0.000 \\
\hline & Systolic blood pressure & 0.003 & 0.000 & 0.095 & 2.122 & 0.034 \\
\hline & Blood glucose & 0.025 & 0.004 & 0.190 & 5.640 & 0.000 \\
\hline & Alcohol consumption & 0.048 & 0.011 & 0.149 & 4.390 & 0.000 \\
\hline & Body mass index & 0.008 & 0.003 & 0.134 & 2.966 & 0.003 \\
\hline & Pulse pressure & -.002 & 0.001 & -0.128 & -2.162 & 0.031 \\
\hline \multirow[t]{6}{*}{ ApoA1/ApoB } & Waist circumference & -0.010 & 0.003 & -0.166 & -3.507 & 0.000 \\
\hline & Body mass index & -0.027 & 0.007 & -0.185 & -3.961 & 0.000 \\
\hline & Age & -0.003 & 0.001 & -0.096 & -2.681 & 0.000 \\
\hline & Gender & 0.224 & 0.046 & 0.222 & 4.869 & 0.000 \\
\hline & Cigarette smoking & 0.186 & 0.043 & 0.193 & 4.309 & 0.000 \\
\hline & Blood glucose & -0.023 & 0.11 & -0.075 & -2.080 & 0.038 \\
\hline \multicolumn{7}{|l|}{ Mulao } \\
\hline \multirow[t]{3}{*}{ TC } & Age & 0.017 & 0.004 & 0.155 & 4.412 & 0.000 \\
\hline & Body mass index & 0.056 & 0.016 & 0.126 & 3.587 & 0.000 \\
\hline & Cigarette smoking & 0.250 & 0.088 & 0.100 & 2.845 & 0.005 \\
\hline \multirow[t]{2}{*}{ TG } & Waist circumference & 0.058 & 0.008 & 0.239 & 6.886 & 0.000 \\
\hline & Alcohol consumption & 0.479 & 0.097 & 0.171 & 4.920 & 0.000 \\
\hline \multirow[t]{4}{*}{ HDL-C } & Body mass index & -0.024 & 0.008 & -0.166 & -3.068 & 0.002 \\
\hline & Alcohol consumption & 0.091 & 0.020 & 0.158 & 4.541 & 0.000 \\
\hline & Age & 0.004 & 0.001 & 0.111 & 3.239 & 0.001 \\
\hline & Waist circumference & -0.007 & 0.003 & -0.144 & -2.630 & 0.009 \\
\hline \multirow[t]{4}{*}{ LDL-C } & Age & 0.011 & 0.003 & 0.133 & 3.715 & 0.000 \\
\hline & Body mass index & 0.039 & 0.012 & 0.120 & 3.317 & 0.001 \\
\hline & Alcohol consumption & -0.152 & 0.046 & -0.117 & -3.270 & 0.001 \\
\hline & Diastolic blood pressure & 0.006 & 0.003 & 0.075 & 2.002 & 0.046 \\
\hline \multirow[t]{2}{*}{ ApoA1 } & Alcohol consumption & 0.105 & 0.019 & 0.196 & 5.449 & 0.000 \\
\hline & Waist circumference & -0.004 & 0.002 & -0.091 & -2.541 & 0.011 \\
\hline \multirow[t]{3}{*}{ ApoB } & Waist circumference & 0.010 & 0.002 & 0.149 & 4.049 & 0.000 \\
\hline & Gender & -0.090 & 0.041 & -0.080 & -2.200 & 0.028 \\
\hline & Blood glucose & 0.025 & 0.012 & 0.077 & 2.145 & 0.032 \\
\hline ApoA1/ApoB & Waist circumference & -0.020 & 0.003 & -0.223 & -6.321 & 0.000 \\
\hline
\end{tabular}

TC, total cholesterol; TG, triglyceride; HDL-C, high-density lipoprotein cholesterol; LDL-C, low-density lipoprotein cholesterol; ApoA1, apolipoprotein A1; ApoB, apolipoprotein $B ; A p o A 1 / A p o B$, the ratio of apolipoprotein $A 1$ to apolipoprotein $B$

Mulao and Han populations, biologically, Mulao and Han nationalities may be homologous. Also, there were no significant differences in the genotypic and allelic frequencies of GALNT2 rs2144300 and rs4846914 SNPs in different races [24].

The potential relationship between the GALNT2 polymorphisms and plasma or serum lipid levels in humans has been evaluated in several previous GWA studies. However, previous findings on the association of these SNPs with the changes in plasma lipid levels are inconsistent. Several studies reported that the minor allele of GALNT2 polymorphisms was associated with low HDLC [17,19-25] and high TG blood levels [15,17,24-28]. In the present study, we showed that the subjects with TT genotype of rs2144300 in Mulao nationality had lower serum TG levels than the subjects with CC genotype in females. The participants with CT/TT genotype of rs2144300 in Han had lower TG and ApoB levels and higher HDL-C, ApoA1 levels, and the ratio of ApoA1 to $A p o B$ in males, and higher LDL-C and ApoB levels in females than the participants with $\mathrm{CC}$ genotype. The individuals with GA/AA genotype of rs4846914 in Mulao nationality had higher TC and LDL-C levels than the individuals with GG genotype in males. The subjects with AA genotype of rs4846914 in Han had higher LDL-C and ApoB levels and lower HDL-C levels and the ratio of ApoA1 to ApoB than the subjects with GG genotype. The levels of TC in Mulao nationality were 
correlated with the genotypes of rs4846914 in males. The levels of ApoA1 in Han were correlated with the genotypes of both SNPs, and the levels of HDL-C, $A p o B$, and the ratio of ApoA1 to ApoB were associated with the genotypes of rs2144300 in males. The levels of LDL-C in Han were correlated with the genotypes of rs4846914 in females. Several GWA and candidate gene studies, however, failed to find a significant association between the GALNT2 polymorphisms and plasma lipid levels [29-31]. In a previous study, Polgár et al. [29] could not detect any effect of the GALNT2 rs4846914 variant on serum TC and TG levels. The mean blood lipid concentrations did not significantly differ in heterozygous and homozygous carriers from those of the non-carriers in either the stratified stroke subgroups or the overall stroke disease group. In Whitehall II, there was a significant association of the GALNT2 polymorphisms and plasma levels of the lipoprotein (a). However, a meta-analysis of the six studies did not confirm any of these findings [31]. This may be because of that the effects of these variants were modest on lipid concentrations or lower statistical power for detecting the association was present $[29,37]$. Also, different genetic and environmental factors might lead to variable levels of associations in different populations.

It is well known that environmental factors such as dietary patterns, lifestyle, obesity, physical activity, and hypertension are all strongly related with serum lipid levels $[7,8]$. In the present study, we also showed that serum lipid parameters were correlated with age, sex, alcohol consumption, cigarette smoking, BMI, and blood pressure in both ethnic groups. These data suggest that the environmental factors also play an important role in determining serum lipid levels in our populations. Although rice and corn are the staple foods in both ethnic groups, the people of Mulao nationality like to eat cold foods along with acidic and spicy dishes, so bean soy sauce and pickled vegetables are among their most popular dishes. They also like to eat animal offals which contain abundant saturated fatty acid. For nearly 50 years it has been widely accepted that high-fat diets, particularly those that contain large quantities of saturated fatty acids, raise blood cholesterol concentrations and predispose individuals to cardiovascular disease [38]. We also found that the percentages of subjects who consumed alcohol were higher in Mulao than in Han nationalities. Although the effects of alcohol intake on LDL-C appear to vary by specific patient types or patterns of alcohol intake, and perhaps by population and sex, this topic has been the focus of much recent research [39]. A recent study in older Italian subjects (65-84 years old) has found that alcohol intake increases serum LDL-C levels [40]. Another recent study of Turks also found increases in LDL-C, as well as in ApoB and TG, with alcohol in men, while women had decreased TG and no change in LDL-C or ApoB with alcohol [41].

\section{Conclusion}

The present study shows that the genotypic and allelic frequencies of GALNT2 rs2144300 and rs4846914 SNPs were not different between the Mulao and Han populations, or between the males and females in both ethnic groups. But the association of GALNT2 polymorphisms and serum lipid levels is different between the two ethnic groups. These differences in the association of GALNT2 polymorphisms and serum lipid profiles between the two ethnic groups might partly result from different GALNT2-enviromental interactions.

\section{Acknowledgements}

This study was supported by the National Natural Science Foundation of China (No: 30960130)

\section{Author details}

${ }^{1}$ Department of Cardiology, Institute of Cardiovascular Diseases, the First Affiliated Hospital, Guangxi Medical University, Nanning, Guangxi, People's Republic of China. 'Department of Molecular Biology, Medical Scientific Research Center, 22 Shuangyong Road, Nanning 530021, Guangxi, People's Republic of China.

\section{Authors' contributions}

QL participated in the design, undertook genotyping, and helped to draft the manuscript. RXY conceived the study, participated in the design, carried out the epidemiological survey, collected the samples, and drafted the manuscript. TTY, LM, XLC, XJH, LHHA and DFW carried out the epidemiological survey and collaborated to the genotyping. JZW and WXL carried out the epidemiological survey and collected the samples. All authors read and approved the final manuscript.

\section{Competing interests}

The authors declare that they have no competing interests.

Received: 1 September 2011 Accepted: 20 September 2011 Published: 20 September 2011

\section{References}

1. Shekelle RB, Shryock AM, Paul O, Lepper M, Stamler J, Liu S, Raynor WJ Jr: Diet, serum cholesterol, and death from coronary heart disease. The Western Electric study. N Engl J Med 1981, 304:65-70.

2. Austin MA: Plasma triglyceride as a risk factor for coronary heart disease. The epidemiologic evidence and beyond. Am J Epidemiol 1989, 129:249-59.

3. National Cholesterol Education Program (NCEP) Expert Panel on Detection, Treatment of High Blood Cholesterol in Adults (Adult Treatment Panel III): Third Report of the National Cholesterol Education Program (NCEP) Expert Panel on Detection, Evaluation, and Treatment of High Blood Cholesterol in Adults (Adult Treatment Panel III) final report. Circulation 2002, 106:3143-421.

4. Kwiterovich PO Jr, Coresh J, Smith HH, Bachorik PS, Derby CA, Pearson TA: Comparison of the plasma levels of apolipoproteins $B$ and $A-1$, and other risk factors in men and women with premature coronary artery disease. Am J Cardiol 1992, 69:1015-21.

5. Hokanson JE, Austin MA: Plasma triglyceride level is a risk factor for cardiovascular disease independent of high-density lipoprotein cholesterol level: a meta-analysis of population-based prospective studies. J Cardiovasc Risk 1996, 3:213-319.

6. Teslovich TM, Musunuru K, Smith AV, Edmondson AC, Stylianou IM, Koseki M, Pirruccello JP, Ripatti S, Chasman DI, Willer CJ, Johansen CT, Fouchier SW, Isaacs A, Peloso GM, Barbalic M, Ricketts SL, Bis JC, 
Aulchenko YS, Thorleifsson G, Feitosa MF, Chambers J, Orho-Melander M, Melander O, Johnson T, Li X, Guo X, Li M, Shin Cho Y, Jin Go M, Jin Kim Y, Lee JY, Park T, Kim K, Sim X, Twee-Hee Ong R, Croteau-Chonka DC, Lange LA, Smith JD, Song K, Hua Zhao J, Yuan X, Luan J, Lamina C, Ziegler A, Zhang W, Zee RY, Wright AF, Witteman JC, Wilson JF, Willemsen G, Wichmann HE, Whitfield JB, Waterworth DM, Wareham NJ, Waeber G, Vollenweider P, Voight BF, Vitart V, Uitterlinden AG, Uda M, Tuomilehto J, Thompson JR, Tanaka T, Surakka I, Stringham HM, Spector TD, Soranzo N, Smit JH, Sinisalo J, Silander K, Sijbrands EJ, Scuteri A, Scott J, Schlessinger D, Sanna S, Salomaa V, Saharinen J, Sabatti C, Ruokonen A, Rudan I, Rose LM, Roberts R, Rieder M, Psaty BM, Pramstaller PP, Pichler I, Perola M, Penninx BW, Pedersen NL, Pattaro C, Parker AN, Pare G, Oostra BA, O'Donnell CJ, Nieminen MS, Nickerson DA, Montgomery GW, Meitinger T, McPherson R, McCarthy Ml, McArdle W, Masson D, Martin NG, Marroni F, Mangino M, Magnusson PK, Lucas G, Luben R, Loos RJ, Lokki ML, Lettre G, Langenberg C, Launer LJ, Lakatta EG, Laaksonen R, Kyvik KO, Kronenberg F, König IR, Khaw KT, Kaprio J, Kaplan LM, Johansson A, Jarvelin MR, Janssens AC, Ingelsson E, Igl W, Kees Hovingh G, Hottenga JJ, Hofman A, Hicks AA, Hengstenberg C, Heid IM, Hayward C, Havulinna AS, Hastie ND, Harris TB, Haritunians T, Hall AS, Gyllensten U, Guiducci C, Groop LC, Gonzalez E, Gieger C, Freimer NB, Ferrucci L, Erdmann J, Elliott P, Ejebe KG, Döring A, Dominiczak AF, Demissie S, Deloukas P, de Geus EJ, de Faire U, Crawford G, Collins FS, Chen YD, Caulfield MJ, Campbell H, Burtt NP, Bonnycastle LL, Boomsma DI, Boekholdt SM, Bergman RN, Barroso I, Bandinelli S, Ballantyne CM, Assimes TL, Quertermous T, Altshuler D, Seielstad M, Wong TY, Tai ES, Feranil AB, Kuzawa CW, Adair LS, Taylor HA Jr, Borecki IB, Gabriel SB, Wilson JG, Holm H, Thorsteinsdottir U, Gudnason V, Krauss RM, Mohlke KL, Ordovas JM, Munroe PB, Kooner JS, Tall AR, Hegele RA, Kastelein JJ, Schadt EE, Rotter Jl, Boerwinkle E, Strachan DP, Mooser V, Stefansson K, Reilly MP, Samani NJ, Schunkert H, Cupples LA, Sandhu MS, Ridker PM, Rader DJ, van Duijn CM, Peltonen L, Abecasis GR, Boehnke M, Kathiresan S: Biological, clinical and population relevance of 95 loci for blood lipids. Nature 2010, 466:707-13.

7. Ruixing Y, Yuming C, Shangling P, Fengping H, Tangwei L, Dezhai Y, Jinzhen W, Limei Y, Weixiong L, Rongshan L, Jiandong H: Effects of demographic, dietary and other lifestyle factors on the prevalence of hyperlipidemia in Guangxi Hei Yi Zhuang and Han populations. Eur J Cardiovasc Prev Rehabil 2006, 13:977-84.

8. Ruixing Y, Qiming F, Dezhai Y, Shuquan L, Weixiong L, Shangling P, Hai W, Yongzhong $Y$, Feng $H$, Shuming $Q$ : Comparison of demography, diet, lifestyle, and serum lipid levels between the Guangxi Bai Ku Yao and Han populations. J Lipid Res 2007, 48:2673-81.

9. Ruixing $Y$, Yiyang $L$, Meng $L$, Kela L, Xingjiang $L$, Lin $Z$, Wanying $L$, Jinzhen $W$, Dezhai $Y$, Weixiong $L$ : Interactions of the apolipoprotein C-III $3238 \mathrm{C}>\mathrm{G}$ polymorphism and alcohol consumption on serum triglyceride levels. Lipids Health Dis 2010, 9:86.

10. Yin RX, Li YY, Liu WY, Zhang L, Wu JZ: Interactions of the apolipoprotein A5 gene polymorphisms and alcohol consumption on serum lipid levels. PLoS One 2011, 6:e17954.

11. Heller DA, de Faire U, Pedersen NL, Dahlén G, McClearn GE: Genetic and environmental influences on serum lipid levels in twins. N Engl I Med 1993, 328:1150-6.

12. Steinmetz J, Boerwinkle E, Gueguen R, Visvikis S, Henny J, Siest G: Multivariate genetic analysis of high density lipoprotein particles. Atherosclerosis 1992, 92:219-27.

13. Pérusse L, Rice T, Després JP, Bergeron J, Province MA, Gagnon J, Leon AS, Rao DC, Skinner JS, Wilmore JH, Bouchard C: Familial resemblance of plasma lipids, lipoproteins and postheparin lipoprotein and hepatic lipases in the HERITAGE Family Study. Arterioscler Thromb Vasc Biol 1997, 17:3263-9.

14. Kathiresan S, Melander O, Anevski D, Guiducci C, Burtt NP, Roos C, Hirschhorn JN, Berglund G, Hedblad B, Groop L, Altshuler DM, NewtonCheh C, Orho-Melander M: Polymorphisms associated with cholesterol and risk of cardiovascular events. N Engl J Med 2008, 358:1240-9.

15. Kathiresan S, Melander O, Guiducci C, Surti A, Burtt NP, Rieder MJ, Cooper GM, Roos C, Voight BF, Havulinna AS, Wahlstrand B, Hedner T, Corella D, Tai ES, Ordovas JM, Berglund G, Vartiainen E, Jousilahti $P$, Hedblad B, Taskinen MR, Newton-Cheh C, Salomaa V, Peltonen L, Groop L, Altshuler DM, Orho-Melander M: Six new loci associated with blood lowdensity lipoprotein cholesterol, high-density lipoprotein cholesterol or triglycerides in humans. Nat Genet 2008, 40:189-97.
16. Sandhu MS, Waterworth DM, Debenham SL, Wheeler E, Papadakis K Zhao JH, Song $\mathrm{K}$, Yuan $\mathrm{X}$, Johnson T, Ashford S, Inouye M, Luben R, Sims M, Hadley D, McArdle W, Barter P, Kesäniemi YA, Mahley RW, McPherson R, Grundy SM, Wellcome Trust Case Control Consortium, Bingham SA, Khaw KT, Loos RJ, Waeber G, Barroso I, Strachan DP, Deloukas P, Vollenweider P, Wareham NJ, Mooser V: LDL-cholesterol concentrations: a genome-wide association study. Lancet 2008, 371:483-91.

17. Willer CJ, Sanna S, Jackson AU, Scuteri A, Bonnycastle LL, Clarke R, Heath SC, Timpson NJ, Najjar SS, Stringham HM, Strait J, Duren WL, Maschio A, Busonero F, Mulas A, Albai G, Swift AJ, Morken MA, Narisu N, Bennett D, Parish S, Shen H, Galan P, Meneton P, Hercberg S, Zelenika D, Chen WM, Li Y, Scott L, Scheet PA, Sundvall J, Watanabe RM, Nagaraja R, Ebrahim S, Lawlor DA, Ben-Shlomo Y, Davey-Smith G, Shuldiner AR, Collins R, Bergman RN, Uda M, Tuomilehto J, Cao A, Collins FS, Lakatta E, Lathrop GM, Boehnke M, Schlessinger D, Mohlke KL, Abecasis GR: Newly identified loci that influence lipid concentrations and risk of coronary artery disease. Nat Genet 2008, 40:161-9.

18. McGuire E, Roseman S: Enzymatic synthesis of the protein-hexosamine linkage in sheep submaxillary mucin. J Biol Chem 1967, 242:3745-7.

19. Holleboom AG, Vergeer M, Hovingh GK, Kastelein JJ, Kuivenhoven JA: The value of HDL genetics. Curr Opin Lipidol 2008, 19:385-94.

20. Tai ES, Sim XL, Ong TH, Wong TY, Saw SM, Aung T, Kathiresan S, OrhoMelander M, Ordovas JM, Tan JT, Seielstad M: Polymorphisms at newly identified lipid-associated loci are associated with blood lipids and cardiovascular disease in an Asian Malay population. J Lipid Res 2009, 50:514-20

21. Musunuru K, Orho-Melander M, Caulfield MP, Li S, Salameh WA, Reitz RE, Berglund G, Hedblad B, Engström G, Williams PT, Kathiresan S, Melander O, Krauss RM: Ion mobility analysis of lipoprotein subfractions identifies three independent axes of cardiovascular risk. Arterioscler Thromb Vasc Biol 2009, 29:1975-80.

22. Edmondson AC, Braund PS, Stylianou IM, Khera AV, Nelson CP, Wolfe ML, Derohannessian SL, Keating BJ, Qu L, He J, Tobin MD, Tomaszewski M, Baumert J, Klopp N, Döring A, Thorand B, Li M, Reilly MP, Koenig W, Samani NJ, Rader DJ: Dense genotyping of candidate gene Loci identifies variants associated with high-density lipoprotein cholesterol. Circ Cardiovasc Genet 2011, 4:145-55.

23. Sarzynski MA, Jacobson P, Rankinen T, Carlsson B, Sjöström L, Carlsson LM, Bouchard C: Association of GWAS-Based Candidate Genes with HDLCholesterol Levels before and after Bariatric Surgery in the Swedish Obese Subjects Study. J Clin Endocrinol Metab 2011, 96:E953-7.

24. Weissglas-Volkov D, Aguilar-Salinas CA, Sinsheimer JS, Riba L, HuertasVazquez A, Ordoñez-Sánchez ML, Rodriguez-Guillen R, Cantor RM, TusieLuna T, Pajukanta P: Investigation of variants identified in caucasian genome-wide association studies for plasma high-density lipoprotein cholesterol and triglycerides levels in Mexican dyslipidemic study samples. Circ Cardiovasc Genet 2010, 3:31-8.

25. Schjoldager KT, Vester-Christensen MB, Bennett EP, Levery SB, Schwientek T, Yin W, Blixt O, Clausen H: O-glycosylation modulates proprotein convertase activation of angiopoietin-like protein 3: possible role of polypeptide GalNAc-transferase-2 in regulation of concentrations of plasma lipids. J Biol Chem 2010, 285:36293-303.

26. Wang J, Ban MR, Zou GY, Cao H, Lin T, Kennedy BA, Anand S, Yusuf S, Huff MW, Pollex RL, Hegele RA: Polygenic determinants of severe hypertriglyceridemia. Hum Mol Genet 2008, 17:2894-9.

27. Hegele RA, Ban MR, Hsueh N, Kennedy BA, Cao H, Zou GY, Anand S, Yusuf S, Huff MW, Wang J: A polygenic basis for four classical Fredrickson hyperlipoproteinemia phenotypes that are characterized by hypertriglyceridemia. Hum Mol Genet 2009, 18:4189-94.

28. Nakayama K, Bayasgalan T, Yamanaka K, Kumada M, Gotoh T, Utsumi N, Yanagisawa Y, Okayama M, Kajii E, Ishibashi S, Iwamoto S, Jichi Community Genetics Team (JCOG): Large scale replication analysis of loci associated with lipid concentrations in a Japanese population. J Med Genet 2009, 46:370-4.

29. Polgár N, Járomi L, Csöngei V, Maász A, Sipeky C, Sáfrány E, Szabó M, Melegh B: Triglyceride level modifying functional variants of GALTN2 and MLXIPL in patients with ischaemic stroke. Eur J Neurol 2010, 17:1033-9.

30. Reynolds CA, Hong MG, Eriksson UK, Blennow K, Wiklund F, Johansson B, Malmberg B, Berg S, Alexeyenko A, Grönberg H, Gatz M, Pedersen NL, Prince JA: Analysis of lipid pathway genes indicates association of 
sequence variation near SREBF1/TOM1L2/ATPAF2 with dementia risk. Hum Mol Genet 2010, 19:2068-78.

31. Zabaneh D, Kumari M, Sandhu M, Wareham N, Wainwright N,

Papamarkou T, Hopewell J, Clarke R, Li K, Palmen J, Talmud PJ,

Kronenberg F, Lamina C, Summerer M, Paulweber B, Price J, Fowkes G, Stewart M, Drenos F, Shah S, Shah T, Casas JP, Kivimaki M, Whittaker J, Hingorani AD, Humphries SE: Meta analysis of candidate gene variants outside the LPA locus with Lp(a) plasma levels in 14, 500 participants of six White European cohorts. Atherosclerosis 2011, 217:447-51.

32. Xu L, Deng QY, Li SF, Zhou LN, Gong JC, Wei BY: Genetic analysis of Mulao nationality using 15 short tandem repeats. Zhonghua $Y_{i} X_{U} Y_{i}$ Chuan Xue Za Zhi 2008, 25:96-100.

33. People's Republic of China-United States Cardiovascular and Cardiopulmonary Epidemiology Research Group: An epidemiological study of cardiovascular and cardiopulmonary disease risk factors in four populations in the People's Republic of China. Baseline report from the P.R.C.-U.S.A. Collaborative Study. Circulation 1992, 85:1083-96.

34. Ruixing $Y$, Limei $Y$, Yuming $C$, Dezhai $Y$, Weixiong L, Muyan L, Fengping $H$ Jinzhen W, Guangqing Y, Zhenbiao N: Prevalence, awareness, treatment, control and risk factors of hypertension in the Guangxi Hei Yi Zhuang and Han populations. Hypertens Res 2006, 29:423-32.

35. Ruixing Y, Weixiong L, Hanjun Y, Dezhai Y, Shuquan L, Shangling P, Qiming F, Jinzhen W, Jianting G, Yaju D: Diet, lifestyle, and blood pressure of the middle-aged and elderly in the Guangxi Bai Ku Yao and Han populations. Am J Hypertens 2008, 21:382-7.

36. Cooperative Meta-analysis Group of China Obesity Task Force: Predictive values of body mass index and waist circumference to risk factors of related diseases in Chinese adult population. Zhonghua Liu Xing Bing Xue Za Zhi 2002, 23:5-10.

37. Chasman D, Pare G, Ridker P: Population-based genomewide genetic analysis of common clinical chemistry analytes. Clin Chem 2009, 55:39-51.

38. Yu-Poth S, Zhao G, Etherton T, Naglak M, Jonnalagadda S, Kris-Etherton PM: Effects of National Cholesterol Education Program's Step I and Step II dietary intervention programs on cardiovascular disease risk factors: a meta-analysis. Am J Clin Nutr 1999, 69:632-46.

39. Brinton EA: Effects of ethanol intake on lipoproteins and atherosclerosis. Curr Opin Lipidol 2010, 21:346-51.

40. Perissinotto E, Buja A, Maggi S, Enzi G, Manzato E, Scafato E, Mastrangelo G, Frigo AC, Coin A, Crepaldi G, Sergi G, ILSA Working Group: Alcohol consumption and cardiovascular risk factors in older lifelong wine drinkers: the Italian Longitudinal Study on Aging. Nutr Metab Cardiovasc Dis 2010, 20:647-55.

41. Onat A, Hergenc G, Dursunoglu D, Ordu S, Can G, Bulur S, Yüksel H: Associations of alcohol consumption with blood pressure, lipoproteins, and subclinical inflammation among Turks. Alcohol 2008, 42:593-601.

doi:10.1186/1476-511X-10-160

Cite this article as: Li et al:: Association of the GALNT2 gene polymorphisms and several environmental factors with serum lipid levels in the Mulao and Han populations. Lipids in Health and Disease 2011 10:160

\section{Submit your next manuscript to BioMed Central and take full advantage of:}

- Convenient online submission

- Thorough peer review

- No space constraints or color figure charges

- Immediate publication on acceptance

- Inclusion in PubMed, CAS, Scopus and Google Scholar

- Research which is freely available for redistribution 